Revista de Economia e Agronegócio - REA ISSN impresso: 1679-1614

ISSN online: $2526-5539$

Vol. 19 | N. 1 | 2021

Yuri Machado de Souza ${ }^{1}$

ORCID: 0000-0001-5569-8547

Luciano Rodrigues ${ }^{2}$

ORCID: 0000-0001-9579-8729

Daniel Furlan Amaral ${ }^{3}$

ORCID: 0000-0002-0981-2553

1 Mestre em Economia Aplicada pela Universidade de São Paulo yurimachadodesouza95@gmail.com

2 Professor no Programa de Mestrado Profissional em Agronegócio (FGV/EESP)

Doutor em Economia Aplicada pela Universidade de São Paulo luciano.rodrigues@fgv.br

3 Doutor em Economia Aplicada pela Universidade de São Paulo dfamaral@gmail.com

Recebido em: 30/12/2020

Aceito em: 19/07/2021

\section{ANÁLISE ESPACIAL DA DEMANDA POR DIESEL NOS ESTADOS BRASILEIROS}

\section{RESUMO}

As mudanças na dinâmica energética mundial e no funcionamento do mercado brasileiro de combustíveis exigem um entendimento profundo do comportamento do consumo energético nos diferentes setores da economia. Em atenção a isso, no presente trabalho se buscou compreender e mensurar as variáveis que determinam a demanda por diesel nos estados brasileiros. A metodologia empregada utilizou dados em painel e modelos de econometria espacial na avaliação da demanda pelo derivado no período de 2002 a 2016. Os parâmetros estimados indicaram elasticidades preço e renda da demanda por diesel de 0,5275 e 0,4247 , respectivamente. Os resultados também revelaram a importância da dinâmica do agronegócio na demanda por diesel. Em linhas gerais, o crescimento de $1 \%$ no valor da produção agropecuária promove crescimento de $0,1471 \%$ no consumo do derivado fóssil. A análise indicou ainda que a demanda por diesel em um determinado Estado é influenciada pela renda e pela produção agropecuária nos Estados vizinhos. Os resultados obtidos oferecem indicações importantes para formuladores de políticas públicas e para ações empresariais relacionadas ao mercado de diesel no Brasil.

Palavras-chave: Econometria espacial; Planejamento energético; Modelagem estatística; Demanda por combustíveis.

\section{ABSTRACT}

Changes in the global energy sector and in the Brazilian fuel market require a deep understanding of the behavior of energy consumption in different sectors of the economy. In this context, this paper aims to understand and measure the variables that determine the demand for diesel in Brazilian states. The analytical tool used adopted spatial economy models to assess demand for the oil product in the period 2002 to 2016. The estimated parameters indicated price and income elasticities of demand for diesel of -0.5275 and 0.4247 , respectively. The results also revealed the importance of agribusiness dynamics in the demand for diesel. In general terms, the $1 \%$ growth in the value of agricultural production promotes a $0.1471 \%$ increase in the consumption of fossil derivatives. The analysis also indicated that the demand for diesel in a given state is influenced by income and agricultural production in neighboring states. The results obtained offer important indications for public policy makers and for business actions related to the diesel market in Brazil.

Keywords: Spatial econometrics, Energetic planning, Statistical modeling, Fuel demand.

JEL Code: C01, C31, O13, Q41. 


\section{INTRODUÇÃO}

O consumo de diesel comercial no Brasil se expandiu de forma expressiva na última década em função do aumento da demanda por serviços de transporte de passageiros, do seu emprego na geração de energia elétrica e, especialmente, do crescimento do transporte de cargas, com destaque para o agronegócio.

Em paralelo, a partir da Lei Federal n ${ }^{\circ} 11.097$ de 2005, o País desenvolveu o Programa Nacional de Produção e Uso de Biodiesel, que se iniciou com a mistura voluntária em $2 \%$ sobre o diesel comercial entre 2005 e 2007, tornada obrigatória a partir de janeiro de 2008 em percentuais crescentes.

Desde 2005, portanto, o diesel comercial no Brasil é composto por uma mistura de diesel A, de origem mineral, e de biodiesel. Doravante, denominar-se-á por diesel o combustível comercial decorrente dessa mistura, denominado também de diesel $\mathrm{B}$, conforme a definição da resolução da Agência Nacional do Petróleo, Gás Natural e Biocombustíveis (ANP, 2013).

A sustentação da demanda pelo derivado, associada a relativa estagnação na capacidade de refino e da produção nacional de diesel, levou ao aumento expressivo da importação para atendimento do consumo doméstico e alterou substancialmente a logística de escoamento interna. Com efeito, em 2019 o Brasil apresentou importação líquida de 12,96 bilhões de litros de diesel puro para o abastecimento doméstico, representando mais de $20 \%$ da demanda nacional pelo derivado (Figura 1).

Figura 1. Comparação entre produção de diesel A, a importação de diesel $A$, a produção de biodiesel e as vendas de diesel $B$

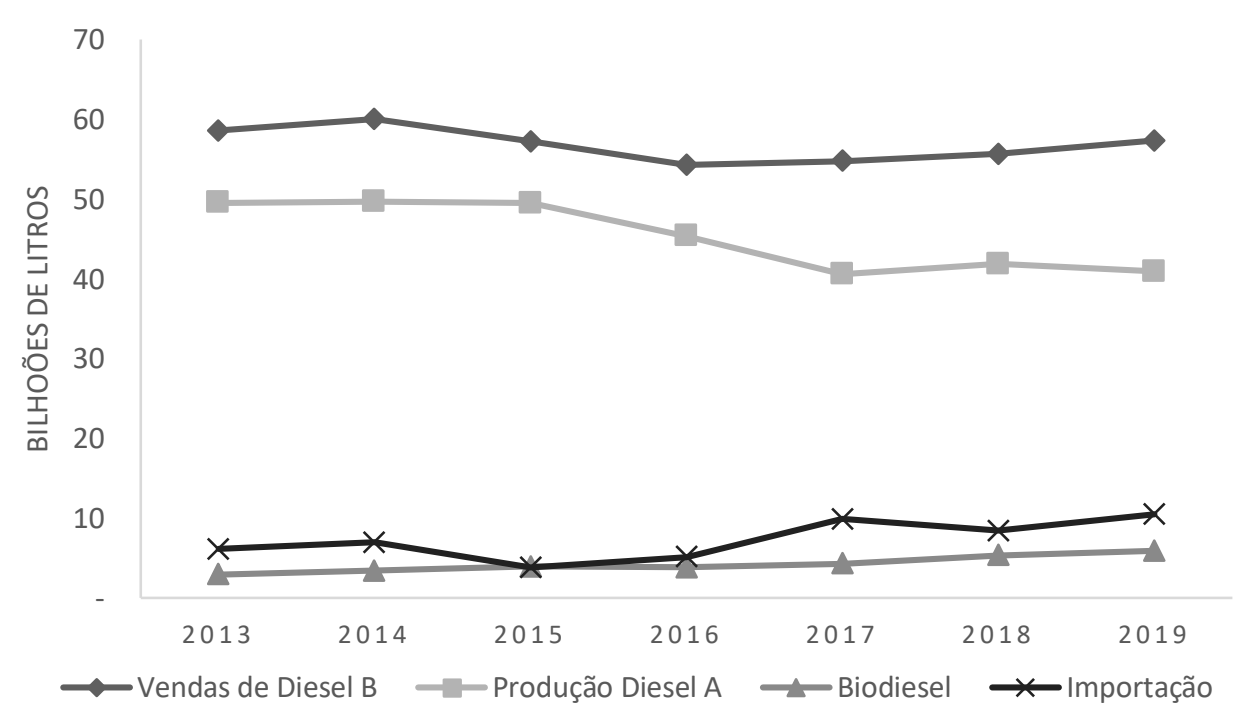

Fonte: Elaboração própria a partir de dados da ANP (2020).

Esse cenário com aumento no consumo em alguns momentos e alterações na estrutura de suprimento de diesel tem gerado preocupação entre os 
agentes que atuam nesse mercado, exigindo uma análise mais estruturada da demanda pelo produto com vistas à consecução de novos investimentos na produção, na logística de importação e na distribuição do derivado.

Necessário contextualizar ainda a importância do diesel para a precificação de fretes rodoviários de cargas. Essa relevância ficou evidente com a paralisação dos transportadores em maio de 2018. Conhecida por "Crise do Diesel", a mencionada greve foi solucionada somente após a publicação de legislação federal que interveio sobre os preços mínimos de fretes, com cláusula específica para os custos do diesel (Brasil, 2018).

A despeito do peso do derivado na matriz nacional de transportes, da sua importância no planejamento energético e das implicações econômicas e sociais associadas a esse mercado, os estudos sobre a demanda brasileira por diesel são escassos e incorporam essencialmente os trabalhos conduzidos por Uchôa et al. (2019), Cardoso e Jesus (2018), Reis (2016) e Luz (2015).

Nesse contexto, este trabalho busca compreender e mensurar as variáveis que impactam a demanda por diesel nos estados brasileiros. Para tanto, além de uma análise lógica e sequencial sobre o assunto, serão estimadas equações de demanda por diesel utilizado para transporte no mercado nacional. A avaliação utiliza ferramentas de econometria espacial e dados disponíveis para o período compreendido entre 2002 e 2016.

O entendimento das variáveis que determinam a demanda por diesel é importante para fundamentar discussões sobre políticas públicas e ações empresariais associadas ao mercado de diesel no Brasil. Cabe ainda destacar a importância da compreensão do fenômeno na definição das metas decenais de descarbonização da Política Nacional de Biocombustíveis (Renovabio).

O trabalho também se justifica por ampliar o conhecimento disponível na literatura sobre o tema. Nesse sentido, Huntington, Barrios e Arora (2017), após realizarem uma ampla revisão dos estudos que avaliaram a demanda por combustíveis no mundo, evidenciaram que apenas 1,93\% dos trabalhos tiveram como objeto de estudo o mercado de diesel.

Ademais, a abordagem metodológica proposta na presente pesquisa é inétida em avaliações dessa natureza. A incorporação de fatores intrínsecos ao mercado nacional, como a influência da produção agropecuária na demanda por diesel, e o uso de modelos que reconhecem a presença de interação espacial no consumo do derivado são elementos ainda não explorados de forma completa na literatura internacional.

Além da introdução a pesquisa conta outras 5 seções, são elas o Mercado de Diesel no Brasil, Revisão de Literatura, Metodologia, Resultados e Discussão e por fim Conclusões. 


\section{O mercado de diesel no brasil}

O consumo brasileiro de diesel se concentra nas regiões Sul e Sudeste do Brasil, que representaram mais de $60 \%$ de todo volume do derivado vendido domesticamente em 2019 (Figura 2). O maior consumo nessas regiões se manteve relativamente estável nos últimos anos e se deve à maior presença populacional e à atividade econômica mais intensa nesses locais.

Figura 2. Participação relativa das unidades da federação nas vendas de diesel em 2019.

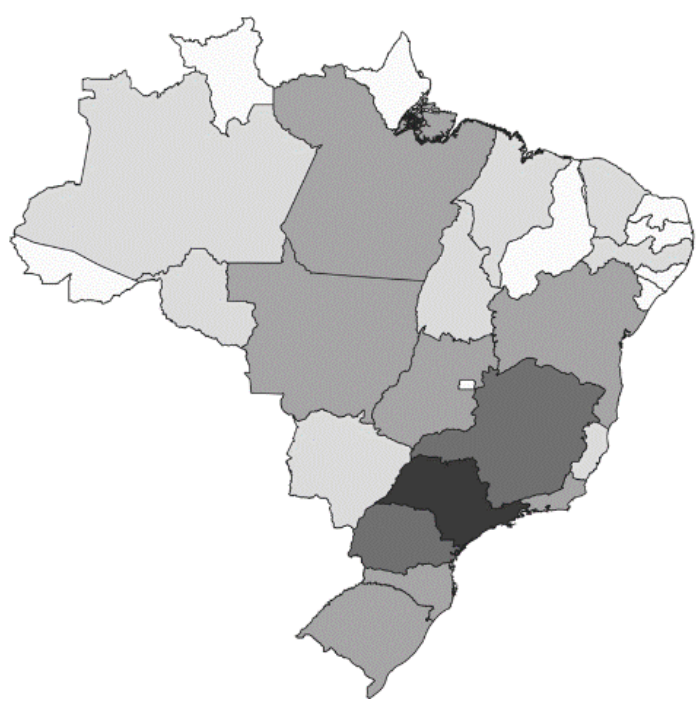

Legenda Quantidade em bilhões de litros vendidos $\square, 10-0,50$ $0,50-1,35$ $1,35-3,50$ $3,50-6,80$ $6,80-12,00$

Fonte: Elaboração própria com dados da ANP (2020).

Como pode ser observado na Figura 3, o uso de diesel para transporte representa quase $90 \%$ de todo o volume comercializado domesticamente. Esse percentual pode ser obtido somando a participação do transporte propriamente dito com as vendas em TRR ${ }^{1}$, as quais são direcionadas especialmente ao uso no transporte rodoviário e em máquinas agrícolas.

\footnotetext{
${ }^{1}$ A sigla TRR faz referência a Transportador-Revendedor-Retalhista, que compreende empresas autorizadas pela ANP a adquirir grandes quantidades de combustível a granel, óleo lubrificante acabado e graxa envasados para depois vender para outras empresas e consumidores (ANP, 2019).
} 
Figura 3. Consumo de diesel por segmento em 2018.

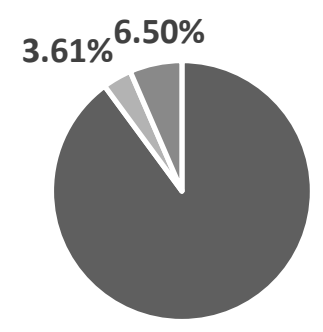

$89.90 \%$

\section{- Automotivo, agrícola e industrial - Embarcações e outros \\ - Ferroviário, mineração e energia}

Fonte: Elaboração própria com dados da ANP (2020).

Outro aspecto relevante a ser mencionado sobre o mercado brasileiro se refere à política interna de precificação dos derivados de petróleo. Com efeito, na Figura 4 são apresentados os preços médios praticados para o diesel mineral (diesel A) ao produtor e para o diesel comercial (diesel B) na distribuidora e na revenda no mercado brasileiro.

Figura 4. Preço nominal do diesel A na refinaria e do diesel B na distribuição e revenda(R\$/L)

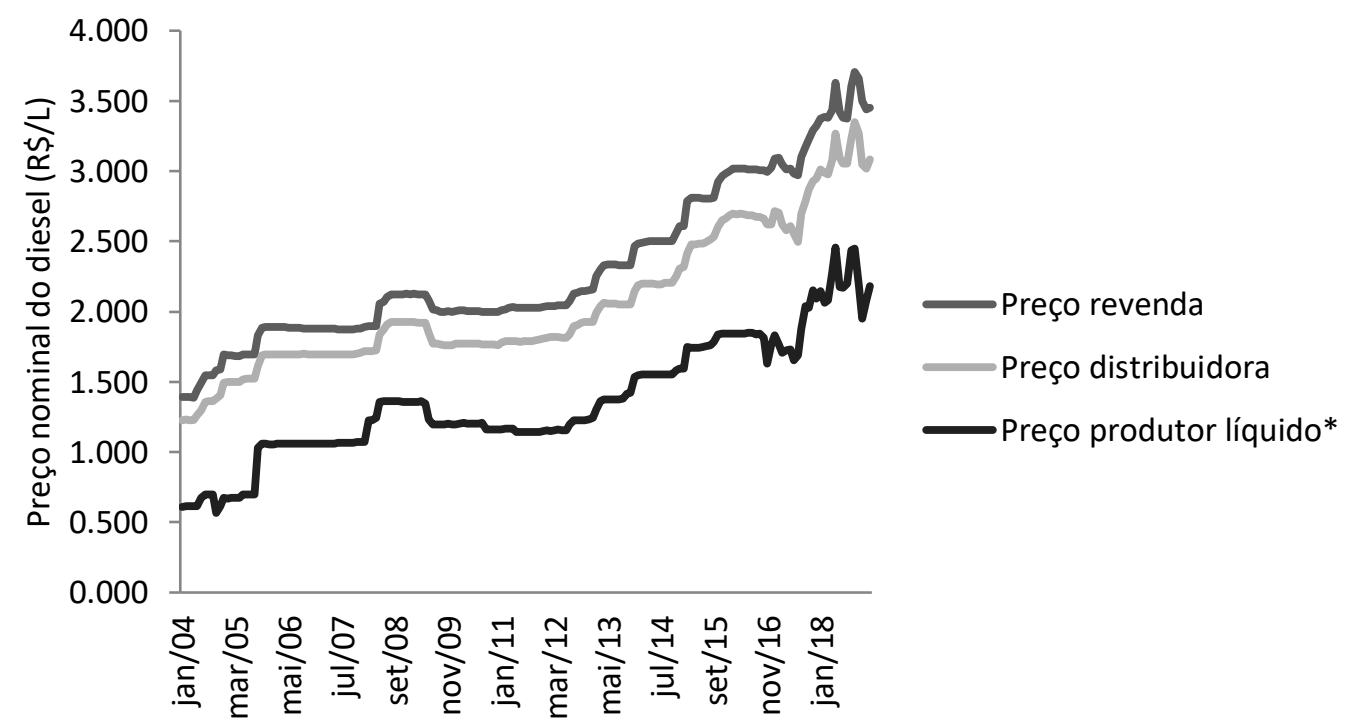

Fonte: Elaboração própria com dados da ANP (2019).

Nota: * preço produtor líquido calculado a partir da diferença entre o preço bruto ao produtor publicado pela ANP (2019) e os impostos que incidem na comercialização desse produto.

No período analisado, é possível observar momentos de estagnação do preço do derivado na refinaria. Conforme discutido por Azevedo e Serigati 
(2015), essa dinâmica atípica de precificação se deu pela intervenção do governo brasileiro nos preços domésticos via política de precificação da Petrobrás, que passou a não reajustar os seus preços de faturamento em muitos momentos, ou redução de tributos federais aplicados ao derivado. Almeida, Oliveira e Losekann (2015) reiteram que esse controle causou disparidade entre os preços doméstico e internacional entre 2011 e 2014.

Essa política, ainda que não de maneira explícita, buscava manter os preços dos derivados em patamares mais reduzidos como forma de atenuar o crescimento da inflação no mercado brasileiro.

O mencionado controle de preços só foi possível porque o abastecimento doméstico do produto é altamente dependente da produção da Petrobrás, cuja participação de mercado na produção brasileira se manteve superior a 95\% desde o início da década de 2000.

Nesse ponto, cabe mencionar ainda que mais de $70 \%$ do preço do diesel pago pelo consumidor é composto pelo preço na refinaria e pelos tributos cobrados sobre o derivado (os tributos federais e estaduais incidentes sobre o produto são recolhidos integralmente pelas refinarias e importadores). A Figura 5 detalha a composição recente do preço do diesel no mercado nacional.

Figura 5. Estrutura típica de formação do preço do diesel.

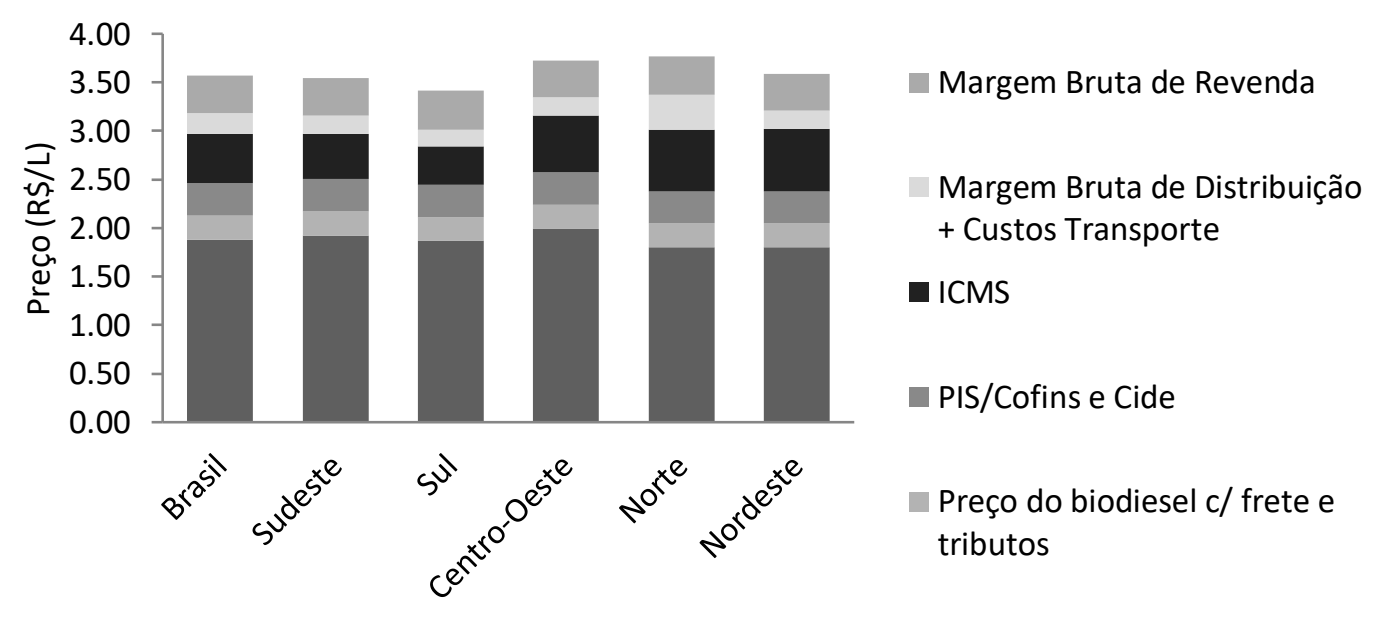

Fonte: Elaboração própria com dados da ANP (2019).

Nota: Estrutura calculada a partir dos preços vigentes em fevereiro de 2019.

Essa breve descrição do mercado de diesel no País evidencia a importância da atividade de transporte na demanda pelo derivado. Nesse contexto, se destaca o modal rodoviário que, segundo a Confederação Nacional do Transporte (CNT, 2018), representou 61\% das cargas e $95 \%$ dos passageiros transportados em 2018.

A essa condição, acrescenta-se que, em média, os caminhões em operação no mercado nacional trafegam mais de $140 \mathrm{mil} \mathrm{km} /$ ano (ESALQ-LOG, 2019; ANTT, 2019). Assim, considerando que a diferença média entre as capitais 
dos estados vizinhos é de 840 km (Agility Logistics, 2019), fica evidente que a distância média percorrida pelos caminhões permite o deslocamento frequente entre as diferentes unidades da federação.

Essa condição justifica a abordagem metodológica sugerida pelo presente estudo, que deve avaliar a demanda considerando a possibilidade de correlação espacial entre os diferentes Estados. Diante da dinâmica apresentada, é natural se esperar que o preço de um Estado possa impactar a demanda por diesel em outro. De forma equivalente, a atividade econômica em uma determinada região pode gerar alteração no consumo de diesel em outra localidade na qual os caminhões trafegaram.

\section{REVISÃO DE LITERATURA}

\section{Literatura disponível sobre a demanda por diesel no mercado brasileiro}

Dentre os trabalhos que avaliaram o mercado nacional, Luz (2015) testou diversos modelos de projeção de consumo de diesel. Ao modelar as demandas regionais, o autor encontrou diferenças significativas na dinâmica da demanda pelo derivado entre os estados da federação e constatou que a inclusão do PIB agrícola foi importante para explicar a sazonalidade do consumo de diesel no país.

Reis (2016), por sua vez, desenvolveu estimativas de demanda tendo como principal objetivo identificar os impactos ambientais da emissão de gases de efeito estufa no setor de transporte brasileiro. Para tanto, o autor estimou um modelo de regressão linear múltipla para estudar o comportamento do consumo de combustíveis no mercado nacional. No caso do diesel, os resultados obtidos evidenciaram que a sua demanda é menos sensível a variações no preço quando comparada à demanda por gasolina e etanol no mercado nacional.

Cardoso e Jesus (2018) utilizaram dados mensais e um modelo de ajustamento parcial para estimar as elasticidades preço e renda da demanda por diesel nos curto e longo prazos. Os autores identificaram que a demanda pelo derivado é inelástica a preço e apresenta elasticidade superior a uma unidade no caso da renda.

Uchôa et al. (2020) também desenvolveram estudo para estimar a demanda por diesel. Os autores utilizaram de dados em painel e os resultados encontrados indicaram elasticidade-preço e elasticidade-renda da demanda pelo derivado de $-1,36$ e 0,15 , respectivamente.

Em linhas gerais, os resultados obtidos na literatura que avaliou o tema no mercado nacional indicam que a demanda por diesel é inelástica a preço para curto e longo prazo. No caso da renda, os resultados não são conclusivos, visto que alguns estudos encontraram parâmetros superiores a uma unidade (Tabela 1). 
Tabela 1. Elasticidades estimadas para o mercado brasileiro de diesel

\begin{tabular}{|c|c|c|c|c|c|c|}
\hline \multirow{2}{*}{ Autor } & \multirow{2}{*}{$\begin{array}{l}\text { Período de } \\
\text { análise }\end{array}$} & \multicolumn{2}{|c|}{$\begin{array}{l}\text { Elasticidade } \\
\text { renda }\end{array}$} & \multicolumn{2}{|c|}{$\begin{array}{l}\text { Elasticidade } \\
\text { preço }\end{array}$} & \multirow[t]{2}{*}{$\begin{array}{l}\text { Modelo } \\
\text { econométrico } \\
\text { empregado }\end{array}$} \\
\hline & & $\begin{array}{l}\text { curto } \\
\text { prazo }\end{array}$ & $\begin{array}{l}\text { longo } \\
\text { prazo }\end{array}$ & $\begin{array}{l}\text { curto } \\
\text { prazo }\end{array}$ & $\begin{array}{l}\text { longo } \\
\text { prazo }\end{array}$ & \\
\hline $\begin{array}{l}\text { Uchôa } \\
\text { et al. } \\
(2020)\end{array}$ & $2007-2016$ & 0,15 & - & $-1,36$ & - & $\begin{array}{c}\text { Modelo de dados } \\
\text { em painel com } \\
\text { variáveis } \\
\text { instrumentais }\end{array}$ \\
\hline $\begin{array}{l}\text { Cardoso } \\
\text { e Jesus } \\
(2018)\end{array}$ & $2003-2018$ & 0,40 & 1,18 & $-0,16$ & $-0,46$ & $\begin{array}{l}\text { Modelo de } \\
\text { ajustamento } \\
\text { parcial }\end{array}$ \\
\hline $\begin{array}{l}\text { Reis } \\
(2016)\end{array}$ & $2001-2012$ & 0,63 & - & $-0,27$ & - & $\begin{array}{l}\text { Regressão linear } \\
\text { múltipla }\end{array}$ \\
\hline $\begin{array}{c}\mathrm{Luz} \\
(2015)\end{array}$ & $2001-2014$ & 0,70 & 0,90 & $-0,30$ & $-0,40$ & $\begin{array}{c}\text { Modelos de séries } \\
\text { temporais com } \\
\text { correção de erros } \\
\text { (ECM) }\end{array}$ \\
\hline $\begin{array}{l}\text { Iooty et } \\
\text { al. } \\
(2009)\end{array}$ & $1970-2005$ & 1,01 & - & $-0,63$ & - & LA-AIDS \\
\hline
\end{tabular}

Fonte: Elaboração própria.

Estudos sobre o mercado de diesel na literatura internacional

A Tabela 2 a seguir traz uma síntese de inúmeros estudos que avaliaram a demanda por diesel na literatura internacional. Esses estudos buscaram estimar as elasticidades renda e preço da demanda pelo derivado a partir de abordagens econométrica distintas. 
Tabela 2. Elasticidades renda e preço da demanda por diesel em outros mercados

\begin{tabular}{|c|c|c|c|c|c|c|c|}
\hline \multirow{2}{*}{ Autor } & \multirow{2}{*}{ País } & \multirow{2}{*}{$\begin{array}{c}\text { Período } \\
\text { de } \\
\text { análise }\end{array}$} & \multicolumn{2}{|c|}{$\begin{array}{l}\text { Elasticidade } \\
\text { preço }\end{array}$} & \multicolumn{2}{|c|}{$\begin{array}{l}\text { Elasticidade } \\
\text { renda }\end{array}$} & \multirow{2}{*}{$\begin{array}{c}\text { Modelo } \\
\text { empregado }\end{array}$} \\
\hline & & & $\begin{array}{l}\text { curto } \\
\text { prazo }\end{array}$ & $\begin{array}{l}\text { longo } \\
\text { prazo }\end{array}$ & $\begin{array}{l}\text { curto } \\
\text { prazo }\end{array}$ & $\begin{array}{l}\text { longo } \\
\text { prazo }\end{array}$ & \\
\hline $\begin{array}{l}\text { Christopoulos } \\
\text { (2000) }\end{array}$ & Grécia & $1970-1990$ & & & & -1.29 & $\begin{array}{l}\text { Estimação } \\
\text { de Zelner } \\
\text { não-linear }\end{array}$ \\
\hline $\begin{array}{l}\text { Dahl e Kurtubi } \\
\qquad(2001)\end{array}$ & Indonésia & 1970-1995 & -0.131 & -0.67 & 2.15 & 2.16 & $\begin{array}{l}\text { Modelo de } \\
\text { correção de } \\
\text { erro (ECM) }\end{array}$ \\
\hline Eltony (2004) & Kuwait & $1980-2000$ & -0.02 & -0.08 & 0.20 & 0.83 & $\begin{array}{l}\text { Mínimos } \\
\text { quadrados } \\
\text { ordinários } \\
\text { (OLS) }\end{array}$ \\
\hline $\begin{array}{l}\text { De Vita, Endresen } \\
\text { e Hunt (2006) }\end{array}$ & Namíbia & 1980-2002 & & -0.11 & & 2.07 & $\begin{array}{c}\text { Autoreg. } \\
\text { Distributed } \\
\text { Lag (ARDL) }\end{array}$ \\
\hline Vasquez (2005) & Perú & $1994-2003$ & 1.28 & -0.43 & 0.24 & 0.70 & $\begin{array}{c}\text { Autoreg. } \\
\text { Distributed } \\
\text { Lag (ARDL) }\end{array}$ \\
\hline Polemis (2006) & Grécia & $1978-2003$ & -0.07 & -0.44 & 0.42 & 1.18 & VECM \\
\hline $\begin{array}{c}\text { Agrawal e } \\
\text { Kumarasamy } \\
\text { (2012) }\end{array}$ & India & $1970-2011$ & & -0.56 & & 1.02 & $\begin{array}{c}\text { Autoreg. } \\
\text { Distributed } \\
\text { Lag (ARDL }\end{array}$ \\
\hline Agrawal (2015) & India & $1970-2012$ & -0.11 & -0.71 & 0.18 & 1.20 & $\begin{array}{c}\text { Autoreg. } \\
\text { Distributed } \\
\text { Lag (ARDL) }\end{array}$ \\
\hline Zeleke (2016) & $\begin{array}{l}\text { União } \\
\text { Européia }\end{array}$ & 1995-2013 & -0.20 & -0.41 & 0.91 & 1.25 & $\begin{array}{l}\text { Modelo de } \\
\text { correção de } \\
\text { erro (ECM) }\end{array}$ \\
\hline Palaiodimos (2017) & Grécia & $2008-2013$ & -0.5 & & 0.91 & & $\begin{array}{c}\text { Equações } \\
\text { simultâneas }\end{array}$ \\
\hline $\begin{array}{c}\text { Liddle e } \\
\text { Huntington (2020) }\end{array}$ & $\mathrm{OCDE}^{*}$ & $1978-2016$ & -0.09 & -0.20 & 0.658 & 1.45 & $\begin{array}{c}\text { Autoreg. } \\
\text { Distributed } \\
\text { Lag (ARDL }\end{array}$ \\
\hline $\begin{array}{c}\text { Liddle e } \\
\text { Huntington (2020) }\end{array}$ & $\begin{array}{l}\text { Não } \\
\text { OCDE }^{* *}\end{array}$ & $1978-2016$ & -0.11 & -0.14 & 0.62 & 0.84 & $\begin{array}{c}\text { Autoreg. } \\
\text { Distributed } \\
\text { Lag (ARDL) }\end{array}$ \\
\hline
\end{tabular}

Fonte: Elaboração própria.

Nota: ${ }^{1}$ Organização para a Cooperação e Desenvolvimento Económico ${ }^{2}$ foram analisados 81 países fora da OCDE. 
Ainda sobre a resposta da demanda por diesel a variações no preço e na renda, Dahl (2012) e Akilu (2016) apresentam uma meta análise sobre os parâmetros estimados por estudos conduzidos em cerca de 124 diferentes países.

A despeito da dificuldade de identificar em detalhes a abordagem econométrica utilizada, os valores encontrados por Dahl (2012) não são divergentes daqueles reportados na Tabela 2.

No caso do preço, a revisão realizada pela autora indica que a mediana das elasticidades foi de -0,16, com distribuição assimétrica à esquerda (Figura 6).

\section{Figura 6. Elasticidades preço da demanda por diesel}

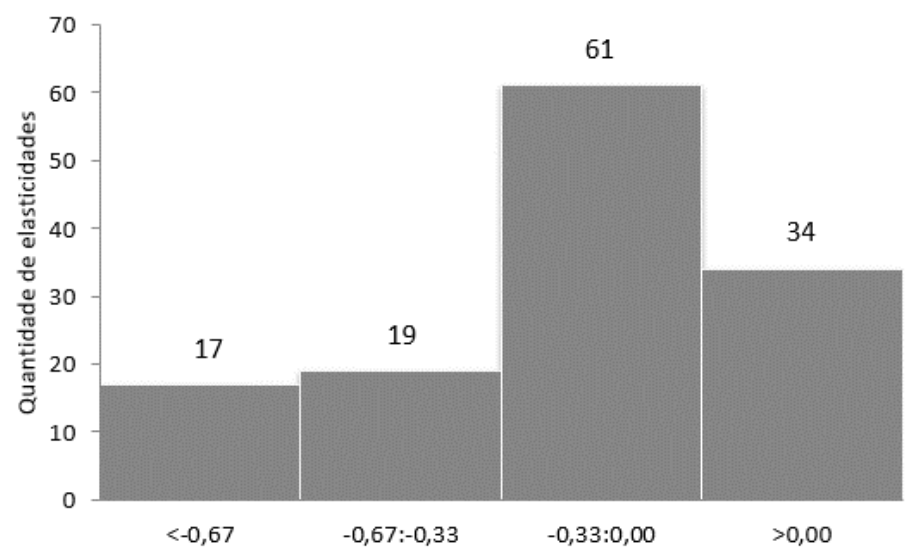

Fonte: Adaptado de Dahl (2012).

Entre os trabalhos analisados por Dahl (2012), a elasticidade renda da demanda por diesel se situou no intervalo entre 0,67 e 1,33, não permitindo, portanto, concluir de forma direta que a demanda pelo derivado é inelástica em relação à renda (Figura 7).

Figura 7. Elasticidades renda da demanda por diesel

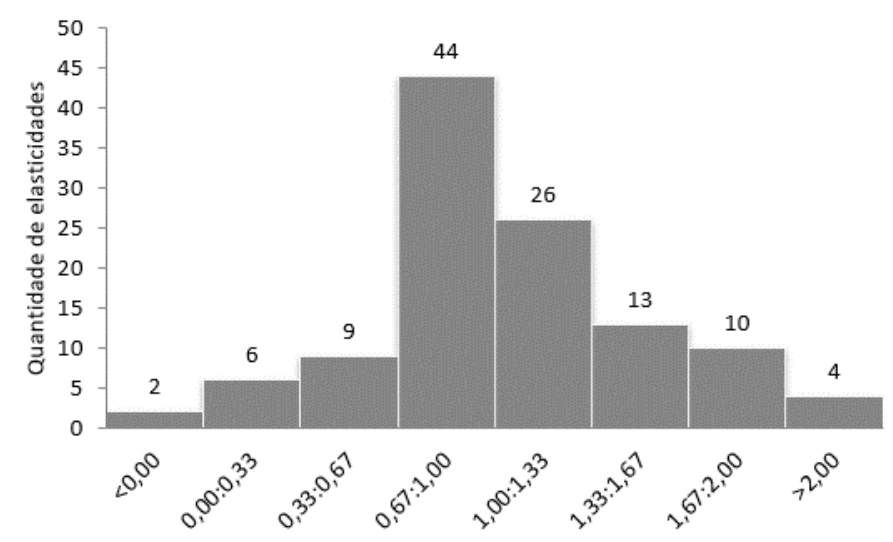

Fonte: Adaptado de Dahl (2012). 
Outro trabalho que traz estimativas de demanda por diesel em diferentes países foi conduzido por Akilu (2016). Em seu estudo, o autor estima a elasticidade preço e renda da demanda por gasolina e diesel para 26 diferentes países europeus. Entre os valores encontrados, constatou que a elasticidade preço da demanda por diesel para o curto prazo se concentrou em torno de $-0,14$ e a elasticidade renda obteve valores variando de 0,5 e 1,0 . Os valores médios para as elasticidades de longo prazo foram -0,49 e 1,36 para elasticidade preço e renda, respectivamente.

Tanto no mercado nacional, quanto no internacional, os estudos sugerem que a demanda pelo diesel é inelástica a preço. No caso da renda, as elasticidades variam de acordo com as condições dos países em termos de desenvolvimento. Nesse caso, não é possível uma conclusão direta e geral sobre a resposta da demanda por diesel a variações na renda.

A partir dos estudos apresentados na Tabela 2, também fica evidente que as elasticidades de longo prazo são usualmente superiores aos parâmetros de curto prazo. Esse resultado já era esperado, visto que alterações no consumo no curto prazo são possíveis apenas por meio da mudança na intensidade de uso da frota disponível. No longo prazo, além do nível de utilização da frota, os consumidores podem optar por veículos com maior eficiência energética, permitindo respostas mais efetivas a variações na renda e no preço do diesel.

Outro aspecto importante identificado nesta revisão refere-se à indicação acerca da importância da dinâmica da produção agropecuária na determinação do consumo de diesel no País.

Por fim, cabe esclarecer que nenhum dos estudos avaliados utilizou estratégia empírica que permitisse avaliar a presença de correlação espacial entre as unidades de análise. Essa condição reitera a contribuição do presente estudo para ampliar o conhecimento sobre o tema na literatura disponível.

\section{METODOLOGIA}

\section{Correlação espacial e demanda energética}

Como descrito anteriormente, no mercado brasileiro o consumo de diesel é predominantemente realizado por caminhões que percorrem diferentes Estados para levar mercadorias à diversos destinos. Nesse contexto, é possível que o preço, a renda e outras variáveis de um estado possam influenciar o consumo de diesel em outra unidade da federação.

A presença de correlação espacial já foi verificada por Santos e Faria (2012) e Cardoso et al. (2020) para estimativas de demanda por etanol e por gasolina no mercado brasileiro, sugerindo que essa característica também pode ser observada no caso do diesel, pois a distância percorrida pelos caminhões é muito superior àquela observada para os veículos leves.

Na literatura internacional, não foram encontrados estudos que analisaram a demanda por diesel utilizando modelos de econometria espacial. A despeito dessa condição, é possível identificar vários trabalhos que utilizaram 
abordagens com controle da correlação espacial no estudo da demanda por outros combustíveis e energia.

Isso posto, a Tabela 3 apresenta uma síntese desses trabalhos. Essa avaliação evidencia que a preocupação aqui apresentada para o emprego de ferramental analítico incorporando a avaliação acerca da presença de correlação espacial não é nova em estudos sobre demanda na área de energia e transporte.

Tabela 3. Resumo dos trabalhos com Econometria Espacial no setor de combustíveis e energia.

\begin{tabular}{|c|c|c|c|c|c|}
\hline Autor(es) & Período de Análise & $\mathbf{N}^{1}$ & Periodicidade & $\begin{array}{l}\text { Modelos } \\
\text { Espaciais }^{2}\end{array}$ & $\begin{array}{l}\text { Variável } \\
\text { explicada }\end{array}$ \\
\hline $\begin{array}{l}\text { Khachatryan, Yan } \\
\text { e Casavant (2011) }\end{array}$ & 2003-2008 & 98 & Mensal & GWR & $\begin{array}{l}\text { Consumo de } \\
\text { etanol }\end{array}$ \\
\hline $\begin{array}{l}\text { Pirotte e Madre } \\
\text { (2011) }\end{array}$ & $1973-1999$ & 21 & Anual & $\begin{array}{l}\text { SAR-FE, SEM-FE, } \\
\text { SAR-RE, SEM-RE }\end{array}$ & Trânisto de carros \\
\hline $\begin{array}{l}\text { Poon, Casas e He } \\
\text { (2013) }\end{array}$ & $1998-2004$ & 30 & Anual & $\begin{array}{l}\text { SAR-MLE, SEM- } \\
\text { MLE }\end{array}$ & Poluição \\
\hline $\begin{array}{l}\text { Allan e McIntyre } \\
\text { (2016) }\end{array}$ & $\begin{array}{c}\text { Abril } 2010 \text { - Junho } \\
2012\end{array}$ & 326 & Mensal & SDM, SDEM & $\begin{array}{l}\text { Consumo de } \\
\text { energia renovável }\end{array}$ \\
\hline $\begin{array}{c}\text { Filippini e } \\
\text { Heimsch (2016) }\end{array}$ & $2001-2008$ & 547 & Anual & SARAR & $\begin{array}{l}\text { Consumo de } \\
\text { gasolina }\end{array}$ \\
\hline Guan e Xu (2016) & $1997-2012$ & 30 & Anual & $\begin{array}{c}\text { SAR- MQO, SEM- } \\
\text { MQO }\end{array}$ & $\begin{array}{l}\text { Consumo de } \\
\text { energia renovável }\end{array}$ \\
\hline $\begin{array}{l}\text { Bowen e Lacombe } \\
\text { (2017) }\end{array}$ & $1990-2012$ & 48 & Anual & $\begin{array}{l}\text { SAR-MQO, SEM - } \\
\text { MQO, SLX-MQO, } \\
\text { SDM-MQO, SDM- } \\
\text { FE(t), SDM-FE, } \\
\text { SDM-FE(t e n) }\end{array}$ & $\begin{array}{l}\text { Consumo de } \\
\text { energia renovável }\end{array}$ \\
\hline $\begin{array}{l}\text { Cabral, Legey e } \\
\text { Cabral (2017) }\end{array}$ & $\begin{array}{l}\text { Janeiro } 2003 \text { - } \\
\text { Dezembro } 2013\end{array}$ & 5 & Mensal & ARIMAsp & $\begin{array}{l}\text { Consumo de } \\
\text { energia }\end{array}$ \\
\hline $\begin{array}{l}\text { Thanos, } \\
\text { Kamargianni e } \\
\text { Schäfer (2017) }\end{array}$ & $2005-2013$ & 105 & Anual & SDM & $\begin{array}{l}\text { Demanda de } \\
\text { transporte }\end{array}$ \\
\hline $\begin{array}{l}\text { Balado-Naves, } \\
\text { Baños-Pino e } \\
\text { Mayor (2018) }\end{array}$ & 1990 - 2014 & 173 & Anual & $\begin{array}{c}\text { SDEM EKC, SLX } \\
\text { EKC }\end{array}$ & Emissão de CO2 \\
\hline Castro (2018) & $1980-2010$ & 212 & nual & SAR-MQO & $\begin{array}{l}\text { Produçãa de } \\
\text { açúcar }\end{array}$ \\
\hline $\begin{array}{c}\text { Eleftheriou, } \\
\text { Nijkamp e } \\
\text { Polemis (2018) }\end{array}$ & $\begin{array}{l}\text { Janeiro } 2012 \text { - } \\
\text { Dezembro } 2015\end{array}$ & 7 & Diário & ASpECM & $\begin{array}{l}\text { Consumo de } \\
\text { gasolina }\end{array}$ \\
\hline Lagarde (2018) & $\begin{array}{c}\text { Janeiro } 1998 \text { - Junho } \\
2016\end{array}$ & 21 & Anual & SAC-FE & $\begin{array}{c}\text { Consumo de } \\
\text { energia renovável }\end{array}$ \\
\hline
\end{tabular}

Fonte: Elaboração própria.

Nota: ${ }^{1} \mathrm{n}$ representa o número de unidades cross-section utilizadas, 2 MQO-

Mínimos Quadrados Ordinários; RE-Random Effect Model; FE-Fixed Effect

Model; SAC-Spatial Autoregressive Combined; SAR-Spatial Autoregressive

Model; SARAR-Spatial Autoregressive Model with Autoregressive Disturbances;

SDEM-Spatial Durbin Error Model; SDM-Spatial Durbin Model; SEM-Spatial

Error Model; SLX-Spatial Lag of X Model. 


\section{Modelo empírico e estratégia de estimação}

A especificação mais utilizada para modelar a demanda por diesel na literatura disponível sobre o tema incorpora o preço do derivado e a renda do consumidor como variáveis que determinam o consumo do produto. Essa lógica é adotada por Cardoso e Jesus (2018), Reis (2016), Luz (2015), Iooty et. al. (2009), Pisa (2012), Zimmer e Koch (2016) e González-Marrero et. al. (2012), entre outros.

No caso brasileiro, entretanto, a descrição até aqui apresentada evidencia a importância da atividade agropecuária para o consumo de diesel. Dessa forma, além da especificação amplamente adotada na literatura sobre o tema, com a renda e o preço do derivado como únicas variáveis determinantes da demanda, foram avaliados modelos incorporando o comportamento da produção agropecuária.

Em função da natureza dos dados e buscando controlar os componentes não observáveis, a estratégia empírica partiu da construção de um painel de dados composto pelos estados brasileiros observados entre os anos de 2002 e 2016². A partir dessa estrutura, a dependência e heterogeneidade espacial foram incorporadas de forma a permitir a estimação de parâmetos consistentes, conforme indicado por Elhorst (2014).

O procedimento de seleção do modelo espacial foi realizado de acordo com a lógica proposta por Halleck Vega e Elhorst (2015). Os autores sugerem como ponto de partida a estimação do modelo regressivo cruzado espacial (SLX), e, se necessário, de modelos que incorporem variáveis autorregressivas (SAR), com erros espacialmente defasados (SEM) ou combinações entre estes e o SLX (SDM ou SDEM), sendo a escolha destes realizada a partir de um critério de performance (nesse caso, foi utilizado o critério de informação de Akaike ou AIC).

Em todos os modelos, foi utilizada uma matriz de ponderação espacial (W) do tipo queen de contiguidade para vizinhos diretos padronizada pela linha. A matriz é formada de modo com que $w_{i j}=0$ para estados que não são vizinhos e $w_{i j}=1$ para estados vizinhos. $\mathrm{O}$ uso dessa matriz pressupõe que a interação no nível estadual se dá apenas pelos vizinhos diretos. Cabe, contudo, ressaltar que outras matrizes de ponderação foram testadas (matriz rook, matriz de distância inversa e matrizes de k-vizinhos mais próximos com k igual a 3, 4 e 5) e os resultados obtidos não apresentaram mudanças relevantes, atestando maior robustez à análise proposta.

Isso posto, as equações (I) a (III) são apresentadas a seguir a partir da notação matricial detalhando cada um dos modelos avaliados. As equações trazem y como variável explicada, definida por um vetor $n x 1 ; \boldsymbol{n}$ o número de observações; $\mathbf{X}$ representa as variáveis explicativas, definido por uma ma-

${ }^{2} \mathrm{O}$ período de análise foi definido em função da disponibilidade de dados até o momento de conclusão da pesquisa. 
triz $n x k$, em que $k$ é o número de parâmetros; $\boldsymbol{\beta}$ retrata os parâmetros estimados, denotados por meio de vetor $k x 1$; e, $\varepsilon$ representa o erro do modelo, com média zero e variância constante.

Assim, o modelo SLX a ser estimado é dado por:

$y=X \beta+W X \tau+\varepsilon$

A modelagem da interação espacial também pode ocorrer assumindo que há endogeneidade espacial (ANSELIN, 2013). Nesse caso, a estrutura a ser estimada é dada pelo modelo SDM definido por:

$y=\rho W y+X \beta+W X \tau+\varepsilon$

O modelo SDEM, por sua vez, incorpora os efeitos espaciais a partir dos erros da equação, conforme especificado a seguir:

$$
\begin{aligned}
& y=X \beta+W X \tau+\varepsilon \\
& \xi=\lambda W \xi+\varepsilon
\end{aligned}
$$

Os modelos (II) e (III) foram estimados por máxima verossimilhança e o modelo (I) por Mínimos Quadrados Ordinários.

Para todos os modelos apresentados nas equações (I) a (III), tem-se: $\boldsymbol{W}$ como matriz de ponderação espacial; $\xi$ como erro com o componente espacial; $\lambda$ é o parâmetro do erro autoregressivo espacial que acompanha a defasagem; $\boldsymbol{\rho}$ é o coeficiente autoregressivo espacial; e, $\boldsymbol{\tau}$ é um vetor de $(k-1)$ por 1 , sendo k o número de parâmetros a serem estimados.

Por fim, cabe mencionar que limitações de eficiência na estimação dos parâmetros devido a endogeneidade de preços na determinação da demanda não estão presentes no problema em análise. Isso porque, como visto anteriormente, no Brasil o preço do diesel é determinado de forma exógena nas refinarias. Esse valor esteve relacionado ao controle de preços praticado pela Petrobrás no início do período em análise e passou a acompanhar as cotações internacionais após a implementação da nova política de preço da empresa.

\section{Dados}

O consumo e os preços de diesel por Estado da Federação foram obtidos junto à Agência Nacional de Petróleo, Gás Natural e Biocombustíveis (ANP, 2019). O PIB anual estadual publicado pelo Instituto Brasileiro de Geografia e Estatística (IBGE, 2019) foi utilizado como indicador de renda e o Valor Bruto da Produção Agropecuária estadual também disponibilizado pelo Instituto (IBGE, 2019) para retratar a dinâmica da produção agropecuária.

As séries monetárias foram convertidas para valores reais de dezembro de 2016 e o consumo foi convertido em valor per capita. Para tanto, utilizou-se 
o IGP-DI anual apurado pela Fundação Getúlio Vargas (FGV, 2019) e a população anual de cada Estado, disponibilizada pelo Instituto Brasileiro de Geografia e Estatística (IBGE, 2019).

Assim, os dados formam um painel, com 27 unidades federativas ao longo de 15 anos, somando 405 observações. A Tabela 4 apresenta a estatística descritiva das séries empregadas.

Tabela 4. Estatística descritiva das variáveis adotadas tomando-se os valores médios para o Brasil (valor anual).

\begin{tabular}{|c|c|c|c|c|c|c|}
\hline Variáveis & Descrição & $\begin{array}{l}\text { Unidade de } \\
\text { medida }\end{array}$ & Média & $\begin{array}{l}\text { Desvio- } \\
\text { Padrão }\end{array}$ & Máx. & Mín. \\
\hline Cons & $\begin{array}{l}\text { Consumo de } \\
\text { diesel }\end{array}$ & $\begin{array}{l}\text { Litros per } \\
\text { capita }\end{array}$ & 262,23 & 151,81 & 849,73 & 66,44 \\
\hline Preço & Preço do diesel & $\mathrm{R} \$$ /litro & 3,15 & 0,33 & 4,37 & 2,43 \\
\hline Renda & PIB per capita & $\begin{array}{l}\mathrm{R} \$ \text { per } \\
\text { capita }\end{array}$ & $23.356,26$ & $13.901,31$ & $83.141,6$ & $5.934,2$ \\
\hline Agro & $\begin{array}{l}\text { Valor bruto da } \\
\text { agropecuária }\end{array}$ & $\begin{array}{l}\mathrm{R} \$ \text { per } \\
\text { capita }\end{array}$ & $1.487,00$ & $1.332,92$ & $7.588,25$ & 130,69 \\
\hline
\end{tabular}

Fonte: Elaboração própria.

A partir da estrutura definida nas equações I, II e III e das variáveis detalhadas na Tabela 4, é possível apresentar a versão genérica das equações empíricas que serão estimadas nas diferentes versões dos modelos.

$$
\begin{gathered}
\text { lnCons }_{i t}=\rho \text { WlnCons }_{i t}+\beta_{1} \text { InPreço }_{i t}+\beta_{2} \text { lnRenda }_{i t} \\
+\beta_{3} \text { InAgro }_{i t}+\tau_{1} \text { WlnRenda }_{i t}+\tau_{2} \text { WlnAgro }_{i t} \\
+\mu_{i}+\varepsilon_{i t} \\
\xi_{i t}=\lambda W \xi_{i t}+\varepsilon_{i t}
\end{gathered}
$$

\section{Recursos computacionais}

Os modelos foram estimados utilizando o software $\mathrm{R}$ (R CORE TEAM, 2018). Os seguintes pacotes foram adotados no processo: Lmtest (ZEILEIS e HOTHORN, 2002), Reshape2 (WICKHAM, 2007), Splm (MILLO e PIRAS, 2012), Sandwich (BERGER, GRAHAM e ZEILEIS, 2017) Spdep (BIVAND e WONG, 2018), Plm (CROISSANT e MILLO, 2018), Car (FOX e WEISBERG, 2019) e Rgdal (BIVAND, KEITT e ROWLINGSON, 2019). 


\section{RESULTADOS E DISCUSSÃO}

A Tabela 5 apresenta o resultado do teste de Hausman (1978). A estatística do teste permite rejeitar a hipótese nula, sugerindo o uso do modelo de dados em painel com efeitos fixos. Assim, foram estimados os modelos espaciais de efeitos fixos SLX, SDM e SDEM.

Tabela 5. Resultado Teste de Hausman

\begin{tabular}{ccc}
\hline Estatística $\chi^{2}$ & p-valor & Resultado \\
\hline 176,49 & 0,0000 & $\begin{array}{c}\text { Rejeita-se a hipótese } \\
\text { nula }\end{array}$ \\
\hline
\end{tabular}

Fonte: Elaboração própria.

Para avaliar a necessidade do uso de modelos espaciais, foi realizado o teste de Pesaran (2007). O referido procedimento avalia a dependência entre as unidades cross-section ao longo do tempo, tendo como hipótese nula a ausência de dependência espacial.

O resultado do teste é apresentado na Tabela 6 e indica a rejeição da hipótese nula, atestando, portanto, a necessidade de incorporação dos efeitos espaciais na estimação dos modelos.

Tabela 6. Resultado teste de Pesaran

\begin{tabular}{ccc}
\hline Estatística $Z$ & p-valor & Resultado \\
\hline 17,6150 & 0,0000 & $\begin{array}{c}\text { Rejeita-se a hipótese } \\
\text { nula }\end{array}$ \\
\hline
\end{tabular}

Fonte: Elaboração própria.

Para selecionar as variáveis a serem defasadas espacialmente, foi realizada uma análise de autocorrelação. Como pode ser observado na Tabela 7, os valores obtidos para a matriz de correlação indicam que o preço e o preço defasado espacialmente (Wpreço) possuem uma elevada correlação (coeficiente de 0,901). 
Tabela 7. Matriz de correlação com variáveis defasadas espacialmente.

\begin{tabular}{ccccccccc}
\hline & consumo & preço & renda & agro & Wconsumo & Wpreço & Wrenda & Wagro \\
\hline Cons & 1 & 0,07 & 0,20 & 0,77 & 0,64 & 0,04 & 0,41 & 0,70 \\
Preço & - & 1 & $-0,11$ & 0,09 & 0,04 & 0,90 & $-0,13$ & $-0,003$ \\
Renda & - & - & 1 & 0,07 & 0,46 & $-0,12$ & 0,63 & 0,38 \\
Agro & - & - & - & 1 & 0,56 & 0,01 & 0,35 & 0,62 \\
Wcons & - & - & - & - & 1 & 0,03 & 0,67 & 0,86 \\
Wpreço & - & - & - & - & - & 1 & $-0,12$ & 0,04 \\
Wrenda & - & - & - & - & - & - & 1 & 0,56 \\
Wagro & - & - & - & - & - & - & - & 1 \\
\hline
\end{tabular}

Fonte: Elaboração própria.

Essa característica pode ter sido influenciada pelo controle de preços realizado no país em boa parte do período em análise. Durante esses anos, as alterações nos valores praticados pelas refinarias eram pontuais e uniformes em todo o território nacional.

Diante desses resultados e da baixa significância estatística da variável Wpreço nos modelos estimados preliminarmente, optou-se pela manutenção das seguintes variáveis nas versões finais dos sistemas: preço, renda, agro, Wrenda e Wagro.

Essas variáveis defasadas espacialmente retratam, pela escolha da matriz de ponderação espacial, a média dos vizinhos diretos de uma determinada região (cada variável com o $W$ anterior a ela representa a sua defasagem espacial).

Assim, seguindo o procedimento proposto por Halleck Vega e Elhorst (2015), foram estimados na sequência os modelos SLX, SDM e SDEM. Os resultados obtidos para as três especificações dos modelos de painel com efeitos fixos são apresentados na Tabela 8. 
Tabela 8. Resultados dos modelos com base em efeitos fixos.

\begin{tabular}{ccccc}
\hline & EF & SLX-EF & SDM-EF & SDEM-EF \\
\hline WCons & - & - & 0,0129 & - \\
$W \xi$ & - & - & - & 0,0565 \\
Preço & $-0,4908^{* * *}$ & $-0,5275^{* * *}$ & $-0,5226^{* * *}$ & $-0,5368^{* * *}$ \\
Renda & $0,6072^{* * *}$ & $0,4247^{* * *}$ & $0,4235^{* * *}$ & $0,4182^{* * *}$ \\
Agro & $0,0821^{*}$ & $0,1471^{* * *}$ & $0,1476^{* * *}$ & $0,1487^{* * *}$ \\
WRenda & - & $0,2361^{*}$ & $0,2281^{*}$ & $0,2398^{*}$ \\
WAgro & - & $-0,1575^{* *}$ & $-0,1584^{* *}$ & $-0,1609^{* *}$ \\
\hline
\end{tabular}

Fonte: Elaboração própria com dados obtidos.

Nota: símbolos *, ** $\mathrm{e}^{* * *}$ denotam, respectivamente, nível de significância estatística de $10 \%, 5 \%$ e $1 \%$.

Os parâmetros estimados para a defasagem na variável explicada $(\hat{\rho})$ e nos erros $(\hat{\lambda})$ não foram estatisticamente significativos. Esses resultados sugerem que os efeitos espaciais foram controlados de maneira eficiente pelo modelo SLX.

A despeito dessa indicação do modelo SLX, é importante mencionar que foi observada certa estabilidade nas elasticidades estimadas a partir dos diferentes modelos espaciais. A elasticidade preço da demanda por diesel foi estatisticamente significativa em todas as versões estimadas e variou de 0,5368 a $-0,4908$.

A elasticidade renda, por sua vez, apresentou uma oscilação um pouco maior, com parâmetros entre e 0,4182 e 0,6072. Essa variação, entretanto, não é suficiente para alterar a interpretação dos resultados, que atestam a baixa elasticidade renda da demanda por diesel no mercado nacional.

Com objetivo de facilitar a comparação dos resultados encontrados neste estudo com aqueles disponíveis na literatura internacional, na Tabela 9 se encontram as elasticidades da demanda estimadas a partir de um modelo de efeito fixo utilizando apenas o preço e a renda como variáveis explicativas. 
Tabela 9. Resultados do modelo EF com preço e renda.

\begin{tabular}{lccc}
\hline & $\begin{array}{c}\text { Valor estimado } \\
\left(\beta_{k}\right)\end{array}$ & Desvio-padrão & p-valor \\
\hline $\ln \operatorname{Preço~}_{i t}\left(\beta_{1}\right)$ & $-0,5075$ & 0,0651 & $0,0000^{* * *}$ \\
$\ln \operatorname{Renda}_{i t}\left(\beta_{2}\right)$ & 0,6520 & 0,0327 & $0,0000^{* * *}$ \\
\hline
\end{tabular}

Fonte: Elaboração própria.

Nota: símbolos *,** $\mathrm{e}^{* * *}$ denotam, respectivamente, nível de significância estatística de $10 \%, 5 \%$ e $1 \%$.

Como pode ser observado, os parâmetros estimados a partir do modelo sem a inclusão do valor da produção agropecuária não apresentam diferenças significativas em relação aos valores detalhados na Tabela 9.

Em linhas gerais, as elasticidades preço estimadas sugerem que a demanda por diesel é inelástica. Esse resultado já era esperado devido à essencialidade do bem e à ausência de produtos substitutos ao diesel no mercado nacional.

Essa característica corrobora os resultados disponíveis na literatura sobre o tema. Na comparação com resultados encontrados por Dahl (2012), a elasticidade obtida ficou mais próxima daquela encontrada em países com menor poder aquisitivo e maior preço do derivado.

Os valores obtidos também estão alinhados com aqueles estimados por outros estudos conduzidos no mercado brasileiro. Conforme parâmetros apresentados na Tabela 1, todos os estudos realizados nacionalmente confirmam a baixa sensibilidade da demanda por diesel a variações no preço do produto.

Essa característica atesta o limitado potencial de redução do consumo do derivado diante de medidas de precificação de carbono para a redução de emissões. Especialmente no mercado nacional, a baixa elasticidade preço da demanda pelo diesel também explica o aumento de tributos federais para ampliação da arrecadação e redução do déficit fiscal no país a partir de 2015.

No tocante à resposta da demanda a alterações na renda disponível, os valores obtidos se situaram no intervalo entre 0,4182 e 0,6072, atingindo 0,4247 no modelo SLX-EF. Portanto, assim como no caso do preço, é possível concluir que a demanda por diesel também é inelástica em relação à renda.

Os parâmetros obtidos são próximos daqueles disponíveis na literatura internacional e apresentados com maior frequência na Figura 7. No caso dos estudos que avaliaram o mercado nacional, apenas os trabalhos de Cardoso e Jesus (2018) e Iooty et al. (2009) encontraram parâmetros levemente superiores a uma unidade. 
No caso do estudo conduzido por Iooty et al. (2009), as comparações devem ser realizadas com ressalvas, pois o autor foi o único que utilizou dados desde 1970 na estimação dos modelos. Considerando que o mercado de diesel no Brasil passou por mudanças significativas ao longo das últimas décadas, é de se esperar que os resultados obtidos a partir da análise conduzida em período recente não apresentem convergência com aqueles estimados com dados mais antigos.

O estudo de Cardoso e Jesus (2018), por sua vez, foi conduzido a partir de um modelo de ajustamento parcial. Essa abordagem permite que sejam estimadas elasticidades de curto e de longo prazo. Considerando as restrições impostas pela impossibilidade de substituição da frota circulante no curto prazo, é natural que os parâmetros estimados para o longo prazo sejam, em termos absolutos, superiores àqueles obtidos para o curto prazo. Essa lógica conceitual justifica, ao menos parcialmente, o fato de os autores terem obtido elasticidade renda para longo prazo superior ao parâmetro estimado na presente pesquisa.

Nesse ponto, cabe ressaltar que uma das principais diferenças entre o Brasil e os demais países na análise da demanda por diesel é a importância do agronegócio no consumo desse combustível. De fato, todos os modelos identificaram uma relação direta e estatisticamente significativa entre a demanda pelo derivado e o valor da produção agropecuária.

Os parâmetros encontrados variaram entre 0,0821 e 0,1487, evidenciando que qualquer aumento na produção da agropecuária deve repercutir em maior consumo por diesel no país. Essa constatação é especialmente importante para direcionar investimentos em logística, visto que a produção do agronegócio cresce em regiões mais distantes dos centros de produção ou de importação do derivado.

Outra contribuição do presente trabalho refere-se à identificação do efeito espacial das variáveis renda e agro. Nesse sentido, os parâmetros estimados devem ser lidos como o impacto do consumo em um determinado estado em decorrência da variação dessa variável nos estados vizinhos. Devido à escolha da matriz de ponderação espacial, essa média retrata a condição dos vizinhos diretos.

O parâmetro estimado para a variável defasada renda no modelo SLX foi 0,2361. A significância estatística sugere que o aumento do consumo em um estado específico está relacionado com uma elevação da renda nos estados vizinhos.

O coeficiente estimado para a variável defasada Wagro, por sua vez, também apresentou significância estatística e atingiu -0,1575 no modelo SLX. O sinal negativo indica uma característica de competição pelo consumo, ou seja, o aumento da produção agrícola média dos vizinhos tende a promover uma redução relativa no consumo de diesel no estado em análise.

Os resultados atestam que o consumo de diesel pode crescer nos próximos anos em decorrência de quedas no preço real do produto, de aumento na renda disponível ou de maior produção da agropecuária. 
As informações obtidas trazem indicações importantes para o direcionamento de investimentos e ações dos agentes privados envolvidos nesse mercado. Adicionalmente, podem ser utilizadas para o delimitar políticas públicas visando a regularidade no abastecimento ou mesmo diretrizes para a expansão da produção doméstica.

No caso do abastecimento, por exemplo, o uso dos parâmetros obtidos para a estruturação de cenários sobre o consumo do derivado é fundamental para dimensionar a necessidade de biodiesel utilizado em mistura com o diesel fóssil ou as metas de descarbonização preconizadas pela recémcriada Política Nacional de Biocombustíveis (RenovaBio).

\section{CONCLUSÕES}

No presente estudo, se buscou investigar o comportamento da demanda de diesel nos Estados brasileiros. As elasticidades encontradas sugerem que a demanda pelo derivado no Brasil é inelástica em relação a preço e a renda, com os parâmetros estimados atingindo -0,5275 e 0,4247, respectivamente. Esses valores corroboram com a maior parte dos resultados encontrados por outros estudos conduzidos no mercado nacional e não apresentam divergência em relação as análises aplicadas em outras regiões do globo.

Apesar desse alinhamento em relação à sensibilidade da demanda a variações na renda e no preço do diesel, uma característica peculiar do mercado nacional que não encontra paralelo em estudos disponíveis para outros países refere-se ao impacto do agronegócio no consumo do derivado. Os resultados obtidos atestam que o aumento de $1 \%$ na produção agropecuária de um determinado estado promove, em média, uma elevação de 0,1471\% no consumo de diesel na mesma unidade da federação.

Adicionalmente, os resultados indicaram a presença de correlação espacial na demanda pelo derivado entre os estados. Especificamente, as variáveis renda e agro defasadas espacialmente apresentaram elasticidades de 0,2361 e $-0,1575$, respectivamente.

Os resultados obtidos possuem implicações importantes para os formuladores de políticas públicas e para melhor planejamento dos agentes que operam nesse setor.

A baixa resposta da demanda por diesel a variações no seu preço, por exemplo, sugere que medidas de precificação de carbono associadas à imposição de imposto mais elevado sobre o derivado podem apresentar menor efetividade na redução de emissões de gases de efeito estufa. Essa condição também evidencia a essencialidade e a ausência de substitutos para esse combustível, retratados na recente greve de caminhoneiros no país. Essa condição indica ainda que o mercado diesel se consubstancia como um importante vetor na arrecadação de tributos federais e estaduais, exigindo análises cuidadosas nas recentes discussões envolvendo as propostas de reforma tributária. 
Os resultados revelam que novos movimentos de crescimento da renda e da produção agropecuária deverão repercutir positivamente na demanda por diesel. Essa condição reforça a necessidade de investimentos em infraestrutura para a logística do derivado, bem como em novos modais para o transporte de cargas no país.

Embora o uso de dados agregados por estado possa ter limitado as evidências dos efeitos espaciais, os resultados permitem afirmar que políticas públicas estaduais voltadas para ampliação da renda ou para estímulo/desestímulo ao agronegócio devem influenciar não apenas o consumo de diesel na unidade da federação em que tais políticas foram aplicadas, mas também nas vizinhas.

Por fim, é preciso reconhecer que este estudo, apesar de ampliar o entendimento do fenômeno, não esgota o tema. Novos trabalhos voltados para a análise do consumo de diesel com dados desagregados por município e com a incorporação de novas variáveis são fundamentais para a melhor compreensão da problemática aqui analisada.

\section{REFERÊNCIAS}

Agility Logistics, 2019, disponível em: <https://www.agility.com/ptpt/homepage/>. Acesso em: 18 abr. 2019.

AKILU, A. Z. Gasoline and diesel demand elasticities: A consistent estimate across the EU-28, Working Paper Series 2016:12, Swedish University of Agricultural Sciences, Department Economics, 2016.

ALLAN, G. J.; MCINTYRE, S. G. Green in the heart or greens in the wallet? The spatial uptake of small-scale renewable technologies. Energy Policy, v. 102, n. September 2016, p. 108-115, 2017.

ALMEIDA, E. L. F.; OLIVEIRA, P. V.; LOSEKANN, L. Impactos da contenção dos preços de combustíveis no Brasil e opções de mecanismos de precificação. Brazilian Journal of Political Economy, v. 35, n. 3, p. 531556, 2015.

ALMEIDA, E. Econometria espacial. Campinas-SP: Alínea, 2012

ANP, 2019, disponível em: <www.anp.gov.br>. Acesso em: 14 mar. 2019.

ANP (Brasil). Resolução n ${ }^{\circ}$ 50, de 23.12.2013 - DOU 24.12.2013. [S. l.],

2013. Disponível em: <http://legislacao.anp.gov.br/ ?path=legislacaoanp/resol-anp/2013/dezembro\&item=ranp-50--2013>. Acesso em: 19 set. 2020.

ANSELIN, L.; FLORAX, R.; REY, S. J. (Ed.). Advances in spatial econometrics: methodology, toMQO and applications. Springer Science \& Business Media, 2013.

ANTAQ, 2019, disponível em: <http://web.antaq.gov.br/anuario/>. Acesso em: 11 jun. 2019. 
AZEVEDO, P. F.; SERIGATI, F. C. Preços administrados e discricionariedade do Executivo. Brazilian Journal of Political Economy, v. 35, n. 3, p. 510-530, 2015.

BALADO-NAVES, R.; BAÑOS-PINO, J. F.; MAYOR, M. Do countries influence neighbouring pollution? A spatial analysis of the EKC for $\mathrm{CO} 2$ emissions. Energy Policy, v. 123, n. September, p. 266-279, 2018.

Baller, R.D., Anselin, L., Messner, S.F., Deane, G., and Hawkins, D.F. Structural covariates of U.S. county homicide rates: Incorporating spatial effects. Criminology 39(3): 561-590, 2001.

BERGER S., GRAHAM N., ZEILEIS A. Various Versatile Variances: An Object-Oriented Implementation of Clustered Covariances in R. Working Paper 2017-12, Working Papers in Economics and Statistics, Research Platform Empirical and Experimental Economics, Universität Innsbruck. URL: http:/ /EconPapers.RePEc.org/RePEc:inn:wpaper:2017-12. 2017.

Biodieselbr, 2019, disponível em:

https://www.biodieselbr.com/noticias/biocombustivel/negocio/import acao-de-diesel-volta-a-superar-marca-de-1-bilhao-de-litros-070519. Acesso em: 20 jun. 2019.

BIVAND, R. S. and WONG, D. W. S. Comparing implementations of global and local indicators of spatial association TEST, 27(3), 716-748. URL https://doi.org/10.1007/s11749-018-0599-x. 2018.

BIVAND R. S., KEITT T. and ROWLINGSON B. rgdal: Bindings for the 'Geospatial' Data Abstraction Library. R package version 1.4-8. https:/ /CRAN.R-project.org/package=rgdal. 2019

BRASIL. Ministério da Indústria e Comércio. Portaria nº 346, de 19 de novembro de 1976 regulamenta a comercialização de veículos movidos a motores com diesel.

BOWEN, E.; LACOMBE, D. J. Spatial dependence in state renewable policy: Effects of renewable portfolio standards on renewable generation within NERC regions. Energy Journal, v. 38, n. 3, p. 177-193, 2017.

CABRAL, J. DE A.; LEGEY, L. F. L.; FREITAS CABRAL, M. V. DE. Electricity consumption forecasting in Brazil: A spatial econometrics approach. Energy, v. 126, p. 124-131, 2017.

CARDOSO, L. C. B.; BITTENCOURT, M. V. L.; PORSSE, A. A.. Demand for light fuels in Brazil an approach using spatial panel data models. Nova econ., Belo Horizonte, v. 30, n. 1, p. 231-256, Jan. 2020

CARDOSO, L. C. B.; JESUS, C. S. DE. Elasticidades da Demanda por Diesel no Brasil. Anpec, p. 1-20, 2018.

CASTRO, L. S. DE. Recent panorama of sugarcane in Brazil: aspects of spatial convergence in production, $30 \mathrm{TH}$ Internacional Conference of Agricultural Economists. Anais. 2018 
CNT, 2019, disponível em: <https://www.cnt.org.br/home>. Acesso em: 18 abr. 2019.

CROISSANT Y, MILLO G. Panel Data Econometrics in R: The plm Package. Journal of Statistical Software, 27(2), 1-43. doi:

10.18637/jss.v027.i02 (URL: https://doi.org/10.18637/jss.v027.i02). 2008

DAHL, C. A. Measuring global gasoline and diesel price and income elasticities. Energy Policy, v. 41, p. 2-13, 2012.

ELEFTHERIOU, K.; NIJKAMP, P.; POLEMIS, M. L. Asymmetric price adjustments in US gasoline markets: impacts of spatial dependence on the "rockets and feathers" hypothesis. Regional Studies, p. 1-14, 2018.

ELHORST, J. P. Spatial econometrics: from cross-sectional data to spatial panels. Heidelberg: Springer, 2014.

Equipe de Desenvolvimento do QGIS (2019). Sistema de Informações Geográficas do QGIS. Projeto Código Aberto Geospatial Foundation. Disponível em: <http://qgis.osgeo.org>. Acesso em: ???

ESALQ-LOG/ANTT, 2019, disponível em:

<https://participantt.antt.gov.br/Site/AudienciaPublica/VisualizarAviso AudienciaPublica.aspx?CodigoAudiencia=378>. Acesso em: 18 abr. 2019.

FGV, 2019, disponível em: <https://portalibre.fgv.br/>. Acesso em: 07 mar. 2019.

FILIPPINI, M.; HEIMSCH, F. The regional impact of a CO2 tax on gasoline demand: A spatial econometric approach. Resource and Energy

Economics, v. 46, p. 85-100, 2016.

FOX J. and WEISBERG S. An $\{\mathrm{R}\}$ Companion to Applied Regression, Third Edition. Thousand Oaks CA: Sage. URL:

https://socialsciences.mcmaster.ca/jfox/Books/Companion/. 2019.

GREENE, W. H. Econometric analysis 7th edition. International edition, New Jersey: Prentice Hall, 2012.

GONZÁLEZ-MARRERO, R. M.; LORENZO-ALEGRÍA, R. M.; TENERIFE, S. C. DE. A Dynamic Model for Road Gasoline and Diesel Consumption: An Application for Spanish Regions. International Journal of Energy Economics and Policy, v. 2, n. 4, p. 201-209, 2012.

GUAN, W.; XU, S. Study of spatial patterns and spatial effects of energy eco-efficiency in China. Journal of Geographical Sciences, v. 26, n. 9, p. 1362-1376, 2016.

HALLECK VEGA, S.; ELHORST, J. P. The SLX model. Journal of Regional Science, v. 55, n. 3, p. 339-363, 2015.

HAUSMAN, J. A. Specification tests in econometrics. Econometrica: Journal of the econometric society, p. 1251-1271, 1978.

HUNTINGTON, H. G.; BARRIOS, J. B.; ARORA, V. Review of Key International Demand Elasticities for Major Industrializing Economies. Energy Modeling Forum Stanford University, 2017. 
IBGE, 2019, disponível em: < https://www.ibge.gov.br>. Acesso em: 06 abr. 2019.

IOOTTY, M.; PINTO Jr, H.; EBELING, F. Automotive fuel consumption in Brazil: Applying static and dynamic systems of demand equations. Energy Policy, 2009.

KHACHATRYAN, H.; YAN, J.; CASAVANT, K. Spatial Differences in Price Elasticity of Demand for Ethanol. Journal of the Transportation Research Forum, v. 50, n. 3, p. 43-61, 2011.

KIM, J.; ZHANG, M. Determining Transit's Impact on Seoul Commercial Land Values: An Application of Spatial Econometrics. International Real Estate Review, v. 8, n. 1, p. 1-26, 2005.

LAGARDE, C. M. DE. Network connection schemes for renewable energy in france: a spatial analysis. Chaire European Eletricity Markets, v. 12.2018, 2018.

LUZ, M. R. Modelo de projeção de demanda de diesel no Brasil: Uma análise nacional e regional. FGV Tese de Doutorado, 2015.

MDIC, 2019, disponível em: <http://www.mdic.gov.br/>. Acesso em: 02 abr. 2019.

MILLO G., PIRAS G.. splm: Spatial Panel Data Models in R. Journal of Statistical Software, 47(1), 1-38. URL http://www.jstatsoft.org/v47/i01/. 2012.

PESARAN, M. Hashem. A simple panel unit root test in the presence of cross-section dependence. Journal of applied econometrics, v. 22, n. 2, p. 265-312, 2007.

PIROTTE, A.; MADRE, J. A Spatial Panel Data Analysis of French Regions. Journal of Transport Economics and Policy, v. 45, n. September 2011, p. 341-365, 2011.

PISA, V. The demand for motor fuels in the central european region and its impacts on indirect tax revenues. Charles University Prague, Faculty of Humanities, 2012.

POON, J. P. H.; CASAS, I.; HE, C. The Impact of Energy, Transport, and Trade on Air Pollution in China. Eurasian Geography and Economics, v. 47, n. 5, p. 568-584, 2008.

R Core Team (2019). R: A language and environment for statistical computing. R Foundation for Statistical Computing, Vienna, Austria. URL https://www.R-project.org/.

REIS, M. T. Análise do Consumo de Combustíveis Líquidos e Emissões no Setor de Transportes no Brasil. POLI/UFRJ, 2016.

SANTOS, G. F.; FARIA, W. R. Spatial Panel Data Models and Fuel Demand in Brazil. Texto para Discussão Nereus, v. 10-2012, 2012. 
THANOS, S.; KAMARGIANNI, M.; SCHÄFER, A. Car Travel Demand: Spillovers and Asymmetric Price Effects in a Spatial Setting.

Transportation Science, v. 52, n. 3, p. 621-636, 2017.

UCHÔA, Frederico et al. Fuel Demand Elasticities in Brazil: A Panel Data Analysis with Instrumental Variables. International Journal of Energy Economics and Policy, v. 10, n. 2, p. 450-457, 2020.

WICKHAM H. Reshaping Data with the reshape Package. Journal of Statistical Software, 21(12), 1-20. URL http://www.jstatsoft.org/v21/i12/. 2007.

WOOLDRIDGE, J. Econometric Analysis of Cross Section and Panel Data, MIT Press, 2002.

ZIMMER, A.; KOCH, N. Fuel Consumption Dynamics in EuropeImplications of Fuel Tax Reforms for Air Pollution and Carbon Emissions from Road Transport. Available at SSRN 2813534, 2016.

ZEILEIS A., HOTHORN T. Diagnostic Checking in Regression Relationships. R News 2(3), 7-10. URL https://CRAN.Rproject.org/doc/Rnews/. 2002 